\title{
Magnitude and factors associated with anemia among pregnant women attending antenatal care in public health centers in central zone of Tigray region, northern Ethiopia: a cross sectional study
}

Teklit Grum $^{1 *}$, Ermyas Brhane ${ }^{2}$, Solomon Hintsa ${ }^{3}$ and Gizienesh Kahsay ${ }^{1}$

\begin{abstract}
Introduction: Anemia is defined as a low blood hemoglobin concentration $(<11 \mathrm{mg} / \mathrm{dl})$. It is a global public health problem especially in pregnant women and is associated with higher risk for both maternal and perinatal mortality and morbidity. In developing countries, like Ethiopia where anemia is common, determining the magnitude and identifying factors that are associated with anemia is necessary to control it.

Methods: Facility based cross sectional study design were conducted among 638 pregnant women attending antenatal care in public health centers in central zone of Tigray region, Northern Ethiopia from November 1/2017 to January 30/2018 using stratified multi stage sampling method. The data was collected through interviewing the pregnant women face to face after getting informed consent using structured and pre-tested questionnaire. The data was coded and entered in to Epi-info 7 then exported to Stata 14 for cleaning and further analysis. Both Bivariable and multi variable logistic regression model was used in the data analysis.

Results: The overall magnitude of anemia (hemoglobin level < $11 \mathrm{mg} / \mathrm{dl}$ ) were found that 16.88\% (95\% Cl: 13.95\%, $19.8 \%)$. Factors which were significantly associated with anemia in the multivariable analysis were: history of malaria attack 1 year prior to study period ( $\mathrm{AOR}=4.73,95 \% \mathrm{Cl}: 2.64,8.46)$, women who had history of excessive menstrual bleeding ( $A O R=3.94,95 \% \mathrm{Cl}: 2.11,7.35)$, unplanned pregnancy ( $\mathrm{AOR}=2.5,95 \% \mathrm{Cl}: 1.4,4.42)$ and three times or less meal frequency $(\mathrm{AOR}=1.89,95 \% \mathrm{Cl}: 1.02,3.5)$.

Conclusion: The magnitude of anemia among pregnant were found that $16.88 \%$. Malaria attack, excessive menstrual bleeding, pregnancy planning and meal frequency were found that significantly associated with anemia in the multivariable analysis. Pregnant women are recommended to increase meal frequency. Health providers should give attention to pregnant women who had history of malaria attack, excessive menstrual bleeding and women whose pregnancy were not planned.
\end{abstract}

Keywords: Anemia, Pregnant women, Ethiopia

\footnotetext{
*Correspondence: teklitvip@gmail.com

'Department of Reproductive Health, College of Health sciences, Aksum

University, Aksum, Ethiopia

Full list of author information is available at the end of the article
}

(c) The Author(s). 2018 Open Access This article is distributed under the terms of the Creative Commons Attribution 4.0 International License (http://creativecommons.org/licenses/by/4.0/), which permits unrestricted use, distribution, and reproduction in any medium, provided you give appropriate credit to the original author(s) and the source, provide a link to the Creative Commons license, and indicate if changes were made. The Creative Commons Public Domain Dedication waiver (http://creativecommons.org/publicdomain/zero/1.0/) applies to the data made available in this article, unless otherwise stated. 


\section{Introduction}

Anemia is defined as a low blood hemoglobin concentration [1]. It is a global public health problem affecting people in all age groups with major consequences for human health as well as social and economic development [1-3]. Anemia is a common health problem in pregnant women which is wider in developing countries than developed countries. As a result, it is associated with higher risk of low birth weight and both maternal and perinatal mortality and morbidity [4-7].

In developing countries, pregnant women are prone to anemia due to low socioeconomic conditions. The poor nutritional intake, repeated infections, frequent pregnancies and low health-seeking behaviors are associated with anemia $[5,8]$.

Since anemia is more common in child bearing women especially during pregnancy in Ethiopia, national nutritional strategies are formulated to reduce as part of the health sector transformation plan [9]. In countries like Ethiopia where anemia due to nutritional deficiencies mainly related to iron deficiency are the major causes $[10,11]$, identifying factors that are associated with anemia is necessary to control it. So, this study is aimed at assessing the magnitude and factors associated with anemia in pregnant women attending antenatal care.

\section{Methods}

\section{Study design}

Facility based cross sectional study design was conducted.

\section{Study area and period}

The study was conducted in central zone of Tigray region, Northern Ethiopia from November 1/2017 to January 30/ 2018. Central zone of Tigray is one of the six zones found in Tigray region. According to the 2007 census, Central zone of Tigray has 12 districts with estimated population of 1,500,000. Out of these population 750,000 are females and 750,000 are males. Central zone of Tigray has 66 health facilities (one referral hospital, 3 general hospitals, 6 primary hospitals and 56 health centers). The antenatal care (ANC) coverage of zone administration is $90 \%$.

\section{Source population}

All pregnant women who attend ANC in public health centers in central zone of Tigray region during the study period.

\section{Study population}

All pregnant women who attend ANC at randomly selected public health centers in central zone of Tigray region during the study period.

\section{Inclusion and exclusion criteria Inclusion criteria}

Pregnant women who attend 1st ANC visit and above at the same health center. Hence hemoglobin level of pregnant women was taken from base line assessment during 1st ANC visit as routine activities before starting any intervention.

\section{Exclusion criteria}

Women who attend 1st ANC other than the selected health center.

\section{Sample size determination}

The sample size was calculated using single proportion formula using epinfo-7 from study conducted in north west Ethiopia where the proportion of women with anemia was $25.2 \%$ [12].

Therefore, the total sample size was calculated using the assumption of marginal error 0.05 , and $95 \%$ confidence interval. Based on these assumptions, the sample size was estimated as 290. After multiplying by 2 for design effect and adding $10 \%$ of non-respondents, the final sample size was determined as 638 study subjects.

\section{Sampling procedures}

Stratified multi stage sampling method was used to select health centers found in the central zone of Tigray region. During the selection of health centers, we stratified them as rural and urban. Two health centers each were randomly selected from 3 randomly selected woreda and one health center from urban in the central zone were included in the study. Proportion to sample size allocation was used to allocate the number of pregnant women from each health facilities by taking 3 months case load pregnant women on ANC visit. Systematic random sampling technique was used to get the study units.

\section{Data collection procedure and tools}

The data was collected through interviewing the pregnant women face to face after getting informed consent using structured and pre-tested questionnaire. The questionnaire was originally developed in English and then translate into Tigrigna (local language). Later on it was translated back to English to ensure its consistency. Finally, it was prepared in Local language (Tigrigna language) to collect data. In addition to that chart review was conducted to extract hemoglobin level at ANC 1st visit and another necessary data from ANC longitudinal register. During data collection, two BSC Degree and 7 diploma holder in nursing were hired as supervisors and data collectors respectively. 


\section{Data analysis}

The data was coded and entered in to Epi-info 7 then exported to Stata 14 for cleaning and further analysis. Both Bivariable and multi variable logistic regression model was used in the data analysis. The assumption of logistic regression model fitness was checked using Hosmer and Lemeshow goodness of fit test statistics. Variables with $P$-value $<0.05$ in the Bivariable logistic regression analysis was considered for inclusion in the multivariable logistic regression analysis to control the effect of confounders.

Variables which were significantly associated with the outcome variable were declared when adjusted odds ratio (AOR) with 95\% confidence interval was significant in the multivariable analysis at $P$-value $<0.05$.

\section{Data quality}

Three days intensive training were given to data collectors and supervisors on the data collection tools and collection procedures by the principal investigator.

Daily supervision of data collectors were made at each health centers during the study period by the supervisors and principal investigator. The collected data were carefully checked for completeness and consistency. Any confusion on the data collection procedure and responses were handled timely.

\section{Results}

Socio-demographic and economic characteristics of study participants

A total of 634 pregnant women were interviewed with the response rate of $99 \%$. The average mean age of study participants was 26.99 years with standard deviation (SD) of 5.99. The majority of age group belongs to 20-34 years which accounts $487(76.81 \%)$. Nearly all $609(96.06 \%)$ of study participants were with orthodox religion. Regarding to marital status, $13(2.05 \%)$ of study participants were not married whereas 552(87.07\%) were married. Eighty five (13.41\%) of participants were with housewife occupation and $277(43.69 \%)$ of the study participants were with primary educational level. Four hundred fifteen $(65.46 \%)$ of the study participant's household size were 1-4 and about a quarter of study participants $127(25.08 \%)$ were with second wealth quintile (Table 1 ).

Out of the total study participants, 175(27.6\%) were nulliparous and $79(16.92 \%)$ had history of abortion. Fifty seven $(12.42 \%)$ and $37(8.06 \%)$ of the study participants were with less than 2 years birth interval and had history of still birth respectively. Regarding to history of malaria attack 1 year prior to this study period, 112(17.67\%) of the study subjects had history of malaria. Most of the participants 542(85.49\%) and 582(91.8\%) had no history of excessive menstrual bleeding and pregnancy related complications respectively. Only 132(20.82\%) of study
Table 1 Socio-demographic and economic characteristics of pregnant women attending ANC in public health centers in central zone of Tigray region, northern Ethiopia, 2018

\begin{tabular}{|c|c|c|}
\hline Variables & Frequency & Percentage \\
\hline \multicolumn{3}{|l|}{ Age in years } \\
\hline $15-20$ & 55 & 8.68 \\
\hline $20-34$ & 487 & 76.81 \\
\hline$\geq 35$ & 92 & 14.51 \\
\hline \multicolumn{3}{|c|}{ Mean $=26.99(S D=5.99)$} \\
\hline \multicolumn{3}{|l|}{ Religion } \\
\hline Orthodox & 609 & 96.06 \\
\hline Muslim & 25 & 3.94 \\
\hline \multicolumn{3}{|l|}{ Marital status } \\
\hline Not married & 13 & 2.05 \\
\hline Married & 552 & 87.07 \\
\hline Divorced & 20 & 3.15 \\
\hline Separated & 46 & 7.26 \\
\hline Others & 3 & 0.47 \\
\hline \multicolumn{3}{|l|}{ Occupation } \\
\hline House wife & 85 & 13.41 \\
\hline Farmer & 399 & 62.93 \\
\hline Merchant & 89 & 14.04 \\
\hline Employee & 43 & 6.78 \\
\hline Others & 18 & 2.84 \\
\hline \multicolumn{3}{|l|}{ Level of education } \\
\hline No formal education & 173 & 27.29 \\
\hline Primary & 277 & 43.69 \\
\hline Secondary & 126 & 19.87 \\
\hline Diploma and above & 58 & 9.15 \\
\hline \multicolumn{3}{|l|}{ Household size } \\
\hline $1-4$ & 415 & 65.46 \\
\hline $5-7$ & 181 & 28.55 \\
\hline$\geq 8$ & 38 & 5.99 \\
\hline \multicolumn{3}{|l|}{ Wealth quintile } \\
\hline Lowest & 127 & 20.03 \\
\hline Second & 159 & 25.08 \\
\hline Middle & 181 & 28.55 \\
\hline Fourth & 60 & 9.46 \\
\hline Highest & 107 & 16.88 \\
\hline
\end{tabular}

subjects were with planned pregnancy. Almost half $315(49.68 \%)$ of the participants were with MUAC less than $23 \mathrm{~cm}$.

The magnitude of anemia (hemoglobin level $<11 \mathrm{mg} /$ dl) were found that $16.88 \%$ (95\% CI: $13.95 \%, 19.8 \%$ ). The mean hemoglobin level of study participants were 12.3 (SD \pm 1.33 . Most of the pregnant women 489 (77.13\%) 
who attend their first ANC were at the 3-6 months of gestational age (Table 2).

The meal frequency of study participants with greater than three times per day were 252(39.75\%). Majority $541(85.33 \%)$ of the total participants were reported that they consume food made from cereals and grains daily. Besides, 179(28.23\%) of the total participants didn't take

Table 2 Obstetric history characteristics of pregnant women attending ANC in public health centers in central zone of Tigray region, northern Ethiopia, 2018

\begin{tabular}{lll}
\hline Variables & Frequency & Percentage \\
\hline Parity & & \\
Nulliparous & 175 & 27.60 \\
$1-4$ & 391 & 61.67 \\
$\geq 5$ & 68 & 10.73
\end{tabular}

Ever had abortion

$\begin{array}{lll}\text { No } & 388 & 83.08 \\ \text { Yes } & 79 & 16.92\end{array}$

Birth interval

$\begin{array}{lll}<2 \text { years } & 57 & 12.42 \\ \geq 2 \text { years } & 402 & 87.58 \\ \text { Had ever still birth } & & \\ \text { No } & 422 & 91.94 \\ \text { Yes } & 37 & 8.06\end{array}$

Have got malaria in previous year

No

Yes

Had excessive menstrual bleeding

No

Yes

Had pregnancy related complication

No

Yes

Planned pregnancy

$$
\begin{aligned}
& \text { No } \\
& \text { Yes }
\end{aligned}
$$

Nutritional status (MUAC)

$$
<23 \mathrm{~cm}
$$

$\geq 23 \mathrm{~cm}$

Hemoglobin level

$$
\begin{aligned}
& <11 \mathrm{mg} / \mathrm{dl} \\
& \geq 11 \mathrm{mg} / \mathrm{dl}
\end{aligned}
$$

Mean 12.38(SD \pm 1.33$)$

HGB level by gestational age (Average HGB level)

$$
\begin{array}{ll}
<3 \text { Months Mean }=12.2(\mathrm{SD} \pm 1.63) & 19 \\
\text { 3-6 Months Mean }=12.22(\mathrm{SD} \pm 1.29) & 489 \\
>6 \text { Months Mean }=12.13(\mathrm{SD} \pm 1.41) & 126
\end{array}
$$

tea or coffee. Concerning to fruit and green leafy vegetables intake, only $11(1.74 \%)$ and $40(6.31 \%)$ of the total study participants reported with daily intake respectively (Table 3).

Socio-demographic factors like; age of women, religion, marital status, occupation, household size and

Table 3 Dietary factors characteristics of pregnant women attending ANC in public health centers in central zone of Tigray region, northern Ethiopia, 2018

\begin{tabular}{lll}
\hline Variables & Frequency & Percentage \\
\hline Meal frequency & & \\
$\leq 3$ times per day & 382 & 60.25 \\
$>3$ times per day & 252 & 39.75
\end{tabular}

Eating food made from cereals, grains

Daily
Weekly
Monthly or above
Drinking tea or coffee

Before meal 73

11.51

Within $1 \mathrm{~h}$

39.27

After $1 \mathrm{~h}$

20.98

Fruit intake

$\begin{array}{lll}\text { No } & 291 & 45.9 \\ \text { Daily } & 11 & 1.74 \\ \text { Weekly } & 266 & 41.96 \\ \text { Monthly or above } & 66 & 10.41\end{array}$

Green leafy vegetables intake

$\begin{array}{lll}\text { No } & 91 & 14.35\end{array}$

$\begin{array}{lll}\text { Daily } & 40 & 6.31\end{array}$

$\begin{array}{lll}\text { Weekly } & 463 & 73.03\end{array}$

Monthly or above $\quad 40 \quad 6.31$

Dairy products/ milk product intake

$\begin{array}{lll}\text { No } & 297 & 46.85\end{array}$

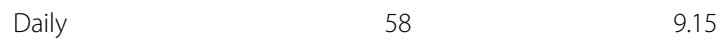

$\begin{array}{lll}\text { Weekly } & 211 & 33.28\end{array}$

Monthly or above $\quad 68 \quad 10.73$

Meat intake

$\begin{array}{lll}\text { No } & 100 & 15.77\end{array}$

$\begin{array}{lll}\text { Daily } & 16 & 2.52\end{array}$

$\begin{array}{lll}\text { Weekly } & 172 & 27.13\end{array}$

Monthly or above $\quad 346 \quad 54.57$

Egg intake

$\begin{array}{lll}\text { No } & 132 & 20.82\end{array}$

$\begin{array}{lll}\text { Daily } & 62 & 9.78\end{array}$

Weekly $343 \quad 54.10$

Monthly or above $\quad 97 \quad 15.30$ 
wealth quintile were not significantly associated with the anemia in Bivariable analysis at $P$-value $<0.05$. Similarly, parity of women, history of abortion, birth interval, history of still birth and nutritional status were not significantly associated with anemia in Bivariable analysis. Regarding to dietary intake, variables which were not significantly associated with anemia in Bivariable analysis at $P$-value $<0.05$ were; eating food made from cereals and grains, drinking tea or coffee, fruit intake, green leafy vegetables intake, dairy products/ milk product intake, meat intake and egg intake.

Variables which were significantly associated with anemia in Bivariable analysis but remains insignificant in multivariable analysis were; women's level of education, birth interval and had pregnancy related complication. However, history of malaria attack 1 year prior to study period, women who had history of excessive menstrual bleeding, planned pregnancy and meal frequency were significantly associated with anemia in the multivariable analysis. Women with history of malaria attack were significantly associated with anemia comparing to women who had no malaria attack $(\mathrm{AOR}=4.73,95 \% \mathrm{CI}$ : $2.64,8.46)$. Comparing to women who had no history of excessive menstrual bleeding, anemia was 3.94 times higher in women with history of excessive menstrual bleeding $(\mathrm{AOR}=394,95 \% \mathrm{CI}: 2.11,7.35)$. Similarly anemia was higher in pregnant women who had no pregnancy planning (AOR $=2.5,95 \% \mathrm{CI}: 1.4,4.42)$ comparing to their counter parts. Meal frequency less than or equal to 3 times per day was also significantly associated with anemia (AOR $=1.89,95 \%$ CI: 1.02, 3.5) (Table 4).

\section{Discussion}

We conducted study aimed on determining magnitude of anemia and factors associated with it. Out of 634 pregnant women included in the study, 107 (16.88\%) were found to be anemic with 95\% CI of 13.95 to $19.8 \%$ which is lower that studies conducted in Woldia (39.1\%) [13], Gode town (56.8\%) [11], Butajira (27.6\%) [5],

Table 4 Bivariable and multivariable analysis of factors associated with anemia among pregnant women attending ANC in public health centers of central zone of Tigray region, northern Ethiopia, 2018

\begin{tabular}{|c|c|c|c|c|}
\hline \multirow[t]{2}{*}{ Variables } & \multicolumn{2}{|l|}{ Anemia } & \multirow[t]{2}{*}{$\operatorname{COR}(95 \%, \mathrm{Cl})$} & \multirow[t]{2}{*}{$\operatorname{AOR}(95 \%, \mathrm{Cl})$} \\
\hline & Yes & No & & \\
\hline \multicolumn{5}{|c|}{ Women's level of education } \\
\hline No formal education & $39(36.45 \%)$ & $134(25.43 \%)$ & 1 & 1 \\
\hline Primary & $35(32.71 \%)$ & $242(45.92 \%)$ & $2.01(1.22,3.33)^{*}$ & $1.53(0.81,2.89)$ \\
\hline Secondary & $20(18.69 \%)$ & $106(20.11 \%)$ & $1.54(0.89,2.8)$ & $0.98(0.43,2.25)$ \\
\hline Diploma and above & $13(12.15 \%)$ & $45(8.54 \%)$ & $1.01(0.49,2.06)$ & $0.52(0.17,1.61)$ \\
\hline \multicolumn{5}{|l|}{ Birth interval } \\
\hline$<2$ years & $16(20.78 \%)$ & $41(10.73 \%)$ & $2.2(1.2,4.13)^{*}$ & $0.57(0.27,1.2)$ \\
\hline$\geq 2$ years & $61(79.22 \%)$ & $341(89.27 \%)$ & 1 & 1 \\
\hline \multicolumn{5}{|c|}{ Malaria attack in last 1 year } \\
\hline No & $64(59.81 \%)$ & $458(86.91 \%)$ & 1 & 1 \\
\hline Yes & $43(40.19 \%)$ & $69(13.09 \%)$ & $4.46(2.8,7.1)^{*}$ & $4.73(2.64,8.46)^{*}$ \\
\hline \multicolumn{5}{|c|}{ Had excessive menstrual bleeding } \\
\hline No & $69(64.49 \%)$ & $473(89.75 \%)$ & 1 & 1 \\
\hline Yes & $38(35.51 \%)$ & $54(10.25 \%)$ & $4.82(2.0,7.84)^{*}$ & $3.94(2.11,7.35)^{*}$ \\
\hline \multicolumn{5}{|c|}{ Had pregnancy related complication } \\
\hline No & $93(86.92 \%)$ & 489(92.79\%) & 1 & 1 \\
\hline Yes & $14(13.08 \%)$ & $38(7.21 \%)$ & $1.94(1.01,3.72)^{*}$ & $1.87(0.77,4.54)$ * \\
\hline \multicolumn{5}{|l|}{ Planned pregnancy } \\
\hline No & $38(35.51 \%)$ & $94(17.84 \%)$ & $2.54(1.61,4.0)$ & $2.5(1.4,4.42)^{*}$ \\
\hline Yes & $69(64.49 \%)$ & $433(82.16 \%)$ & & 1 \\
\hline \multicolumn{5}{|l|}{ Meal frequency } \\
\hline$\leq 3$ times per day & $74(69.16 \%)$ & $308(58.44 \%)$ & $1.6(1.02,2.49)$ & $1.89(1.02,3.5)^{*}$ \\
\hline$>3$ times per day & $33(30.84 \%)$ & $219(41.56 \%)$ & 1 & 1 \\
\hline
\end{tabular}


Nekemt (52\%) [14], Mizan Tepi (23.5\%) [15], Dera (30.5\%) [4] and North West Tigray (36.1\%) [16], but similar with the study conducted in Mekelle (19.3\%) [10]. Overall magnitude of anemia in pregnant women is currently decreasing due to multi-sectorial interventions like increasing health access and economy in the country through time but still it remains a public health problem.

In this finding, pregnant women who had history of malaria attack in the last 1 year prior to study period were found that significantly associated with anemia $(\mathrm{AOR}=4.73,95 \% \mathrm{CI}: 2.64,8.46)$. This finding is similar with the study conducted in North Western zone of Tigray [16], in Dera District, South Gondar Zone [4] and Sunyani Municipal Hospital, Ghana [17] among pregnant women which declared that malaria attack was significantly associated with anemia. This could be explained that parasitic infections especially malaria results destruction of red blood cells [2].

In this study pregnant women with history of excessive menstrual bleeding were 3.94 times more likely to be anemic than those who had normal menstrual bleeding. A study conducted in Mizan Tepi University Teaching Hospital, South West Ethiopia [15] were also reported that heavy menstrual bleeding was significantly associated with anemia. This may be due to low iron reserves following excess bleeding during menstruation period.

Planned pregnancy was found that significantly associated with anemia. Anemia was 2.5 times higher in pregnant women whose pregnancy was not planned (AOR = 2.5, 95\% CI: 1.4, 4.42). Women with their planned pregnancy may prepare prior or early in pregnancy on nutritional intake.

Meal frequency with 3 times or less per day was associated with anemia $(\mathrm{AOR}=1.89,95 \% \mathrm{CI}: 1.02,3.5)$. This study is consistent with Studies conducted in Mekelle town [10] and in North West of Tigray [16]. This implies increased meal frequency during pregnancy needs to fulfill the nutrients demand of pregnant women.

\section{Conclusion}

The magnitude of anemia among pregnant were found that 16.88. Factors that were independently significant with anemia were; history of malaria attack, excessive menstrual bleeding, pregnancy which was not planned and three or less meal frequency per a day. It is recommended that pregnant women should increase meal frequency. Health providers should give attention to pregnant women who had history of malaria attack, excessive menstrual bleeding and women whose pregnancy were not planned to control malaria in pregnancy.

\section{Abbreviations}

ANC: Antenatal care; AOR: Adjusted odds ratio; Cl: Confidence interval; CM: Centimeter; COR: Crude odds ratio; HGB: Hemoglobin; MUAC: Middle upper arm circumference; SD: Standard deviation

\section{Acknowledgments}

We would like to thank Aksum University for financial support of this study. Our thanks goes to directors of public health centers for their cooperation. Finally, we would like to thank the study subjects, data collectors and supervisors for their voluntariness in participating this study.

\section{Funding}

This research has been funded through college of Health sciences, Aksum University.

\section{Availability of data and materials}

The data used during the current study is available from corresponding author.

\section{Authors' contributions}

TG have contributed in the design, data analysis, write up and manuscript development. EB, SH contributed in data collection and analysis. GK contributed to editing and revising of the final manuscript. All authors read and approved the final manuscript.

\section{Ethics approval and consent to participate}

The ethical clearance was approved by Institutional Review Board of College of Health Sciences, Aksum University. In addition to that, permission was obtained from administration and directors of all health facilities. Information about the purpose of the study was given to the participants then informed written consent from pregnant women were obtained before data collection. On behalf of the participants under the age of 16 , written consent was obtained from the parents/legal guardians.

\section{Consent for publication}

Not applicable

\section{Competing interests}

The authors declare that they have no competing interests.

\section{Publisher's Note}

Springer Nature remains neutral with regard to jurisdictional claims in published maps and institutional affiliations.

\section{Author details}

${ }^{1}$ Department of Reproductive Health, College of Health sciences, Aksum University, Aksum, Ethiopia. ${ }^{2}$ Department of Human Nutrition, College of Health sciences, Aksum University, Aksum, Ethiopia. ${ }^{3}$ Department of Epidemiology and Biostatistics, College of Health sciences, Aksum University, Aksum, Ethiopia.

Received: 4 April 2018 Accepted: 17 October 2018

Published online: 01 November 2018

\section{References}

1. United Nations Children's Fund. United Nations University and World Health Organization. Iron Deficiency Anaemia Assessment, Prevention and Control A guide for programme managers. Geneva 2001.

2. WHO and UNICEF. Focusing on anaemia towards an integrated approach for effective anaemia control. Geneva: World health organization; 2004.

3. World Health Organization. The global prevalence of anaemia. Geneva: World health organization; 2011.

4. Derso T, Abera Z, Tariku A. Magnitude and associated factors of anemia among pregnant women in Dera District: a cross-sectional study in Northwest Ethiopia. BMC Res Notes. 2017;10:359.

5. Getahun W, Belachew T, Wolide AD. Burden and associated factors of anemia among pregnant women attending antenatal care in southern Ethiopia: cross sectional study. BMC Res Notes. 2017;10:276.

6. Lelissa D, Yilma M, Shewalem W, Abraha A, Worku M, Ambachew H, et al. Prevalence of Anemia among women receiving antenatal Care at Boditii Health Center, southern Ethiopia. Clin Med Res. 2015:4(3):79-86.

7. Zillmer K, Pokharel A, Spielman K, Kershaw M, Ayele K, Kidane Y, et al. Predictors of anemia in pregnant women residing in rural areas of the Oromiya region of Ethiopia. BMC Nutr. 2017;3(65).

8. Tadesse SE, Seid O, G/Mariam Y, Fekadu A, Wasihun Y, Endris K, et al. Determinants of anemia among pregnant mothers attending antenatal care 
in Dessie town health facilities, northern central Ethiopia, unmatched case -control study. Plose One. 2017;12(3):e0173173.

9. Federal Democratic Republic of Ethiopia Ministry of Health. Health Sector Transformation Plan 2015/16-2019/20. Addis Ababa: Federal democratic republic of Ethiopia ministry of health; 2015.

10. Abriha A, Yesuf ME, Wassie MM. Prevalence and associated factors of anemia among pregnant women of Mekelle town: a cross sectional study BMC Res Notes. 2014;7:888.

11. Alene KA, Dohe AM. Prevalence of Anemia and Associated Factors among Pregnant Women in an Urban Area of Eastern Ethiopia. Cairo: Hindawi Publishing Corporation; 2014

12. Asrie F. Prevalence of anemia and its associated factors among pregnant women receiving antenatal care at Aymiba Health Center, northwest Ethiopia. J Blood Med. 2017;8:35-40.

13. Brhanie TW, Sisay H. Prevalence of Iron deficiency Anemia and determinants among pregnant women attending antenatal Care at Woldia Hospital, Ethiopia. J Nutr Dis Ther. 2016;6(4).

14. Mihiretie H, Fufa M, Mitiku A, Bacha C, Getahun D, Kejela M, et al. Magnitude of Anemia and Associated Factors among Pregnant Women Attending Antenatal Care in Nekemte Health Center, Nekemte, Ethiopia. Med Microbiol Diag. 2015;4(3).

15. Zekarias B, Meleko A, Hayder A, Nigatu A, Yetagessu T. Prevalence of Anemia and its associated factors among pregnant WomenAttending antenatal care (ANC) in Mizan Tepi University teaching hospital, South West Ethiopia. Health Sci J. 2017;11(5,529).

16. Gebre A, Mulugeta A. Prevalence of Anemia and associated factors among pregnant women in North Western zone of Tigray, northern Ethiopia: a cross-sectional study. J Nutr Metab. 2015;2015.

17. Anlaakuu P, Anto F. Anaemia in pregnancy and associated factors: a cross sectional study of antenatal attendants at the Sunyani municipal hospital, Ghana. BMC Res Notes. 2017;10:402

Ready to submit your research? Choose BMC and benefit from:

- fast, convenient online submission

- thorough peer review by experienced researchers in your field

- rapid publication on acceptance

- support for research data, including large and complex data types

- gold Open Access which fosters wider collaboration and increased citations

- maximum visibility for your research: over $100 \mathrm{M}$ website views per year

At $\mathrm{BMC}$, research is always in progress.

Learn more biomedcentral.com/submissions 